\title{
ANALISIS PERANCANGAN TATA LETAK PABRIK PT. XYZ DENGAN METODE ACTIVITY RELATIONSHIP CHART (ARC)
}

\author{
Lintangjati Arum Suminar ${ }^{1)}$, Wahyudin Wahyudin ${ }^{2)}$, Billy Nugraha ${ }^{3)}$ \\ ${ }^{123}$ Fakultas Teknik, Universitas Singaperbangsa Karawang \\ email: lintangjatiarum@gmail.com
}

\begin{abstract}
Abstrak
Abstrak: Perancangan tata letak pabrik merupakan hal penting untuk diperhatikan dalam meningkatkan produktivitas pada perusahaan. PT. XYZ merupakan perusahaan yang bergerak dalam bidang produksi lensa kacamata khususnya kacamata fashion. PT. XYZ terdiri dari divisi-divisi yang saling berkaitan satu sama lain dengan satu tujuan yang sama yaitu mewujudkan tujuan perusahaan. Dalam praktiknya agar produksi dapat berjalan dengan baik. Metode yang digunakan dalam penelitian ini adalah activity relationship chart (ARC). Layout perusahaan memiliki peranan penting untuk meminimalkan biaya dan mengefisiensi pengaturan segala aktivitas produksi di area kerja. Sehingga proses produksi pada perusahaan berjalan dengan lancar. Tujuan penelitian ini dilakukan analisis layout perusahaan agar tercipta sistem produksi yang lebih optimal. Perusahaan menciptakan sistem produksi agar proses produksi berjalan dengan baik dan menghasilkan profit yang maksimal. Hasil dari penelitian memberikan usulan plant layout yang tersistematis untuk proses produksi yang lebih baik. Maka penerapan metode activity relationship chart (ARC) sebagai metode usulan tata letak pabrik yang lebih baik.
\end{abstract}

Kata kunci: Layout, Activity Relationship Chart, Profit

Abstract: The design of the factory layout are important things to consider in increasing the productivity of the company. PT. XYZ is a company engaged in the production of eyeglass lenses, especially fashion glasses. PT. XYZ consists of divisions that are interrelated with one another with the same goal of realizing company goals. In practice so that production can run well. Company layout has an important role in minimizing costs and efficiently managing all production activities in the work area. So that the production process at the company runs smoothly. Therefore, it is necessary to analyze the company's layout in order to create a more optimal production system. The company creates a production system so that the production process can be carried out well and generate maximum profit. To create a good production process, a systematic plant layout is needed. Layout relates to the degree of relationship between activities and departments. So the application of the activity relationship chart (ARC) method is a method for a better factory layout proposal.

Keywords: Layout, Activity Relationship Chart, Profit

\section{PENDAHULUAN}

Dalam praktiknya penelitian ini dilakukan pada divisi produksi, dengan tujuan produksi dapat berjalan dengan baik. Permasalahan yang terjadi di PT. XYZ belum tersistematisnya layout proses produksi. Maka terjadi penambahan waktu dan biaya yang seharunya dapat diminimalkan. Layout perusahaan memiliki peranan penting untuk meminimalkan biaya serta mengefisiensi pengaturan segala aktivitas produksi dan wilayah kerja. Dari hal tersebut maka urgensi yang perlu diperhatikan oleh PT. XYZ adalah perbaikkan layout proses produksi yang lebih tersistematis. Maka proses produksi pada perusahaan dapat berjalan dengan lancar (Ariani, 2009). Oleh karena itu, perlu dilakukan analisis layout pada perusahaan agar tercipta sistem produksi yang lebih optimal. Perusahaan menciptakan sistem produksi agar kegiatan produksi berjalan dengan baik dan menghasilkan keuntungan yang 
maksimal (Haming \& Nurnajamuddin, 2011). Produksi merupakan kegiatan pokok pada perusahaan maupun instansi. Produksi suatu kegiatan untuk menghasilkan nilai tambah pada produk, dengan adanya produksi dapat dikatakan perusahaan tersebut hidup (Heizer \& Render, 2009). Sistem produksi sendiri merupakan sistem integral dengan komponen struktural dan fungsional perusahaan yang dikemas dan disusun sebaik mungkin sehingga tujuan perusahaan dapat tercapai dengan maksimal (Muther, 1955). Untuk mewujudkan terciptanya kegiatan produksi yang baik diperlukan tata letak pabrik yang baik juga. Layout berhubungan dengan derajat hubungan antar aktivitas dan departemen, maka diterapkanlah metode activity relationship chart sebagai hasil usulan tata letak pabrik yang lebih baik.

Tata letak pabrik atau tata letak fasilitas dapat diartikan sebagai tata cara pengaturan fasilitas fisik pabrik, untuk menunjang kelancaran kegiatan produksi (Wignjosoebroto, 2009). Sedangkan menurut pengertian lain, tata letak pabrik suatu susunan fasilitas fisik (perlengkapan, tanah, bangunan, dan sarana lainnya). Untuk mengetahui metode desain layout perlu mengetahui elemen-elemen dasar yang perlu diperhatikan dalam desain pabrik (plant design) yang ruang lingkupnya lebih luas, yakni meliputi: perencanaan financial, penentuan lokasi dan seluruh desain yang diperlukan untuk memenuhi kebutuhan fisik perusahaan. Adapun elemen-elemen dasar desain pabrik adalah: kekuatan pemilik modal, desain produk, perencanaan volume penjualan, pemilihan proses produksi, analisis membuat atau membeli, ukuran pabrik, harga jual produk, lokasi pabrik, tata letak pabrik, pemilihan tipe bangunan pabrik, keanekaragaman atau diversifikasi jenis produk serta pengembangan organisasi (Haming \& Nurnajamuddin, 2011). Sedangkan prosedur atau langkahlangkah desain pabrik yang diperhatikan adalah : riset pasar dan peramalan penjualan atau kebutuhan, kebijaksanaan manajemen, desain produk, desain proses dan kegiatan produksi atau operasional, desain lokasi dan tata letak fasilitas, analisis perhitungan biaya, pengadaan dana, realisasi proyek, proses manufacturing dan distribusi output (Apple, 1990).

Penelitian yang dilakukan oleh Maulina Pramesti, Heru Santoso Hadi Subagyo dan Anisa Aprilia : Tata letak yang dipilih yaitu tata letak layout 1 dengan nilai score 0.97. Tata letak tersebut dapat menghasilkan jarak perpindahan aliran bahan sebesar 26,495 meter serta waktu perpindahan bahan sebesar 326,24 detik (Pramesti, Subagyo, \& Aprilia, 2019).

Penelitian yang dilakukan oleh Nur Muhamad Iskandar, Igna Saffrina Fahin: Hasil perhitungan total jarak perpindahan untuk layout awal sebesar $591 \mathrm{~m}^{2} /$ hari, alternatif pertama sebesar $565 \mathrm{~m}^{2} /$ hari, dan alternatif kedua sebesar $584 \mathrm{~m}^{2} /$ hari. Biaya material handling untuk layout (Iskandar \& Fahin, 2015).

Penelitian yang dilakukan oleh Antoni Yohanes: Berdasarkan hasil running Facility Location and Layout untuk bagian produksi teh hijau PT. Rumpun Sari Medini diperoleh hasil perubahan 2 departemen lebih baik menghasilkan nilai kontribusi yang lebih rendah dari perubahan 3 departemen. Metode Rectilinear Distance perubahan 2 departemen dapat menghasilkan nilai kontribusi 146.479,03 sedangkan perubahan 3 departemen dapat menghasilkan nilai kontribusi 166.617,5 (Yohanes, 2011).

Penelitian yang dilakukan oleh Yenita Morena dan Merry Siska: Berdasarkan hasil pengolahan didapatkan persentase penurunan panjang lintasan material handling layout alternatif 1 dengan layout awal adalah sebesar $74.8 \%$, sedangkan persentase penurunan panjang lintasan material handling layout alternatif 2 
dengan layout awal sebesar $69.5 \%$ (Morena \& Siska, 2011).

Penelitian yang dilakukan oleh: Dwi Agustina, Anastasia Lydia Maukar dan Dian Retno Sari Dewi: Untuk merancang tata letak pabrik pada penelitian ini menggunakan Systematic Layout Planning (SLP). Di mana untuk penyusunan tata letak metode khusus yang digunakan adalah Algoritma CORELAP (Agustina, Maukar, \& Dewi, 2007).

Penelitian yang dilakukan oleh Bambang Herry Purnomo, Andrew Setiawan Rusdianto dan Muhammad Hamdani: Hasil penelitian menunjukkan verifikasi tata letak yang lebih efisien dengan jarak perpindahan awal Total Movement dari 2650,44 meter menjadi 2469,46 meter atau jarak dapat dipersingkat 6,83\% (Purnomo, Rusdianto, \& Hamdani, 2009).

Penelitian yang dilakukan oleh Indah Pratiwi, Etika Muslimah dan Abdul Wahab Aqil: Hasil perhitungan terjadi penurunan jarak model Rectilinear sebesar $1.385 \mathrm{~m} / \mathrm{hari}$, model Square Euclidean sebesar $198.09 \mathrm{~m} / \mathrm{hari}$ dan model Euclidean sebesar $1.38935 \mathrm{~m} / \mathrm{hari}$ (Pratiwi, Muslimah, \& Aqil, 2012).

Penelitian yang dilakukan oleh Ukurta Tarigan, Robby Simbolon, Meilita $\mathrm{T}$. Sembiring, Uni Pratama P. Tarigan, Nurhayati Sembirin dan Indah R. Tarigan: Hasil dari penelitian ini menunjukkan adanya penurunan total momen perpindahan pada lantai produksi PT. ABC dari 14.495,08 meter/bulan menjadi 5930,19 meter/bulan dengan menggunakan algoritma CORELAP dan sebesar 7.369,7 meter/bulan pada algoritma ALDEP (Tarigan, et al., 2019).

Penelitian yang dilakukan oleh Risthia Eriana Putri dan Widodo Ismanto: Penelitian ini menerapkan metode 5S pada penyusunan tata letak fasilitas Alya Jaya Motor untuk memperoleh tata letak yang lebih rapi, yaitu Seiri dan Seiton pada gudang mekanik, Seiso yaitu pada gudang produksi dan semua departemen, Seiketsu dan Shitsuke (Putri \& Ismanto, 2019).
Penelitian yang dilakukan oleh Rionaldi Yulianti, Alex Saleh dan Abu Bakar: Template usulan perbaikan terdiri dari 3 opsi usulan serta usulan yang terpilih berdasarkan kriteria minimisasi ongkos material handling merupakan usulan opsi 3 dimana penempatan mesin diletakkan ke dalam satu atap pabrik dan penempatan jarak antar mesin tidak menggunakan perhitungan allowance (kelonggaran) teoritis (Yulianti, Saleh, \& Bakar, 2014).

Pembaharuan dari penelitian yang dilakukan ini dari penelitian sebelumnya. Pada dasarnya activity relatioship chart ini hampir mirip dengan from to chart, hanya saja analisisnya bersifat kualitatif. Jika pada from to chart analisis dilakukan berdasarkan angka-angka berat/volume dan jarak perpindahan bahan dari satu departemen ke departemen lain. Analisis dilakukan sebagai pengumpulan informasi yang ada. Data tersebut dapat berguna untuk keperluan dalam penelitian ini, analisis juga dilakukan untuk memilah, membedakan, dan menguraikan informasi yang digunakan untuk kepentingan analisis. Tujuan penelitian ini dilakukan analisis layout perusahaan agar tercipta sistem produksi yang lebih optimal. Perusahaan menciptakan sistem produksi agar proses produksi berjalan dengan baik dan menghasilkan profit yang maksimal. Rencana pemecahan masalah yang akan dilakukan dalam penelitian ini, yaitu pemberian usulan layout yang tersistematis. Metode activity relationship chart (ARC) dirasa dapat memecahkan permasalahan yang sedang terjadi. Hasil dari penelitian memberikan usulan plant layout yang tersistematis untuk proses produksi yang lebih baik. Maka penerapan metode activity relationship chart (ARC) sebagai metode usulan tata letak pabrik yang lebih baik.

\section{METODE PENELITIAN}

Metode yang digunakan dalam penelitin ini adalah activity relationship chart (ARC). Hal ini disebabkan sesuai dengan 
permasalahan yang sedang terjadi. Maka hasil yang ditawarkan berupa usulan perbaikan layout proses produksi yang lebih baik. Dengan tujuan utuk meminimalkan waktu atau biaya yang terbuang tidak mendapatkan profit yang diharapkan. Rancangan kegiatan yang dilakukan dalam penelitian ini, yaitu dengan memahami alur proses produksi yang dilakukan oleh PT. XYZ. Didapatkan hasil dari alur proses produksi PT. XYZ yang seharusnya dapat diminimalkan kembali. Maka ruanglingkup dalam penelitian ini untuk menganalisis layout proses produksi di PT. XYZ.

Sedangkan tahapan yang dilakukan dalam menggunakan metode activity relationship chart (ARC) dibuatkan pada Gambar 1. di bawah ini:

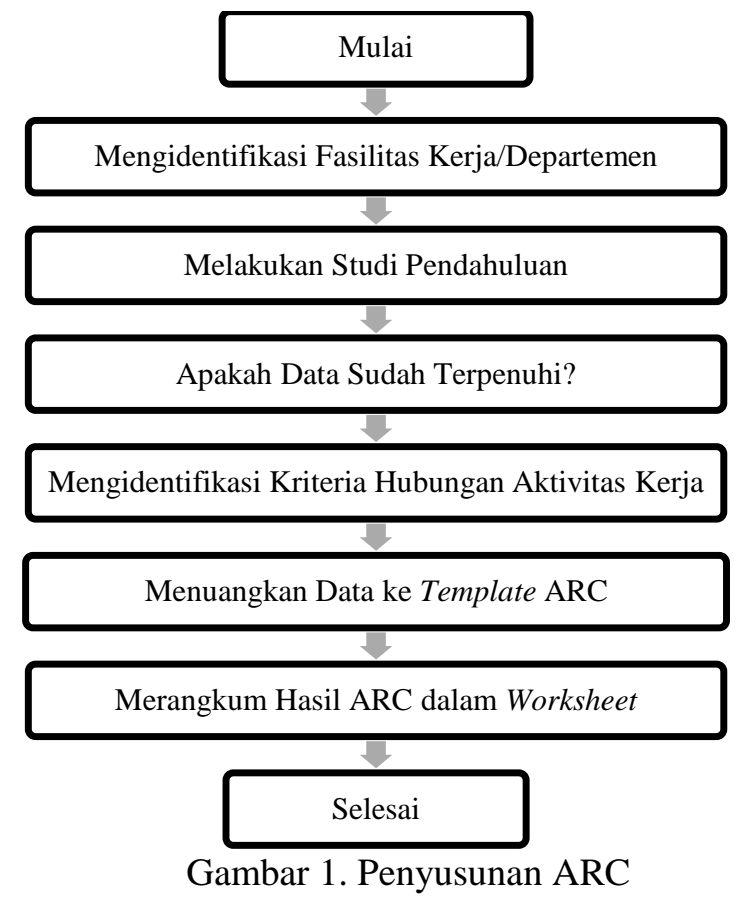

Penjelasan singkat pada Gambar 1. di atas adapun elemen-elemen dasar dalam medesain ulang layout proses produksi adalah: kekuatan pemilik modal, desain produk, perencanaan volume penjualan, pemilihan proses produksi, analisis membuat atau membeli, ukuran pabrik, harga jual produk, lokasi pabrik, tata letak pabrik, pemilihan tipe bangunan pabrik, keanekaragaman atau diversifikasi jenis produk serta pengembangan organisasi.
Teknik pengumpulan data yang dilakukan dalam penelitian ini terbagi menjadi 2, yaitu studi literatur dan studi lapangan. Studi literatur yang dilakukan dengan cara mengumpulkan dan menganalisis sumber referensi ilmiah. Hal ini bertujuan untuk dijadikannya parameter dalam penelitian, khususnya seperti artikel ilmiah atau jurnal penelitian terdahulu. Sedangkan studi lapangan dilakukan dengan cara menganalisis secara langsung di PT. XYZ. Dengan cara mengkaji permasalahan yang terjadi, yaitu layout proses produksi yang seharusnya dapat diminimalkan dalam waktu dan biaya produksi.

Variabel yang diteliti dan akan dilakukan analisis lebih lanjut yaitu layout proses produksi sebagai variabel dependen. Sedangkan untuk acitivity relationship chart (ARC), worksheet dan area allocation diagram (AAD) sebagai variabel independen. Kegiatan menganalisis data dalam penelitian ini meliputi beberapa tahap dasar: Proses editing adalah melakukan edit terhadap data yang telah dikumpulkan dari hasil survei di lapangan. Pada prinsipnya proses editing data bertujuan agar data yang nanti akan dianalisis telah akurat dan lengkap. Proses coding adalah pengubahan data kualitatif menjadi angka. Dengan mengklasifikasikan data ukuran area atau departement yang ada menurut kategorikategori yang penting (pemberian kode). Proses scoring adalah penentuan skor atas urgensi area atau departement yang dilakukan. Dengan membuat klasifikasi dan kategori yang cocok tergantung pada prioritasnya layout proses produksi. Proses visual atau tabulasi adalah menyajikan data yang diperoleh dalam bentuk gambar dan tabel. Sehingga diharapkan pembaca dapat melihat hasil penelitian dengan jelas.

\section{HASIL DAN PEMBAHASAN}

Berikut beberapa hasil dan langkah pembahasan dalam penelitian ini, sebagai berikut: 
1. Membuat Activity Relationship Chart (ARC): Dengan menerapkan langkahlangkah di sebelumnya. Berikut adalah hasil dari pemetaan ruang, seperti pada gambar 2. di bawah ini:

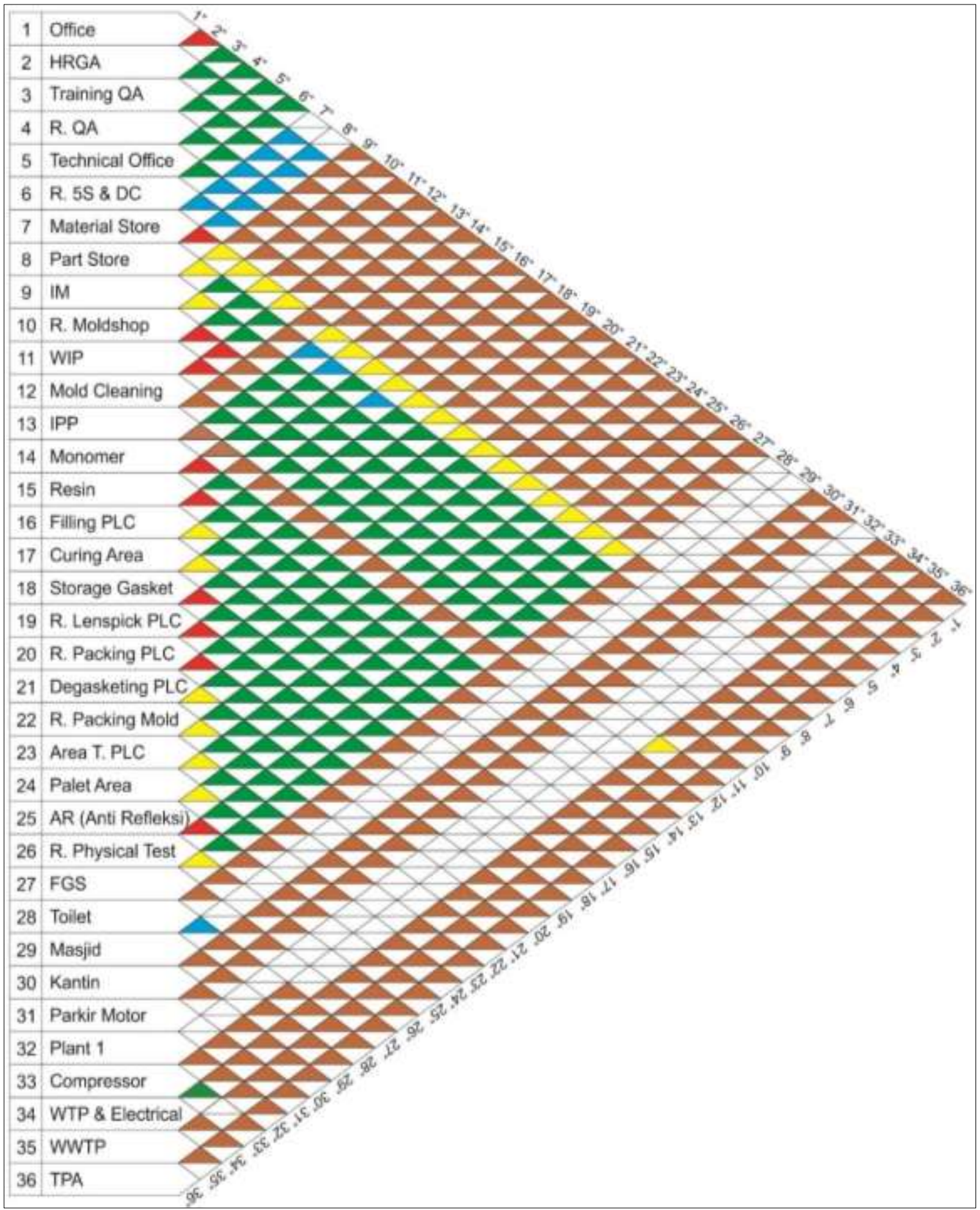

Gambar 2. Hasil Activity Relationship Chart (ARC)

2. Membuat Worksheet (Lembar Kerja): Penyusunan atau pembuatan Worksheet ditujukan untuk merekap atau merangkum hasil pengisian dari metode 
Activity Relationship Control (ARC). Hasil tersebut berisikan tingkat hubungan antar aktivitas atau maupun kegiatan antar departemen yang terdapat pada perusahaan. Adapun hasil

dari pengerjaan Worksheet yang telah disusun berdasarkan Activity Relationship Chart (ARC) di atas seperti pada Tabel 1. di bawah ini:

Tabel 1. Hasil Pengerjaan Worksheet

\begin{tabular}{|c|c|c|c|c|c|c|c|}
\hline \multirow[b]{2}{*}{ No. } & \multirow{2}{*}{ Ruang } & \multicolumn{6}{|c|}{ Derajat Keterdekatan } \\
\hline & & A & E & I & $\mathrm{O}$ & $\mathrm{U}$ & $\mathrm{X}$ \\
\hline 1 & Office & $2 "$ & 0 & $\begin{array}{l}\text { 3",4",5", } \\
\text { 6" }\end{array}$ & 0 & $\begin{array}{c}\text { 7”,8”,28”, } \\
\text { 29”,32”, }\end{array}$ & $\begin{array}{r}9^{\prime \prime},-27^{\prime \prime}, 30^{\prime \prime}, \\
-31 ", 33^{\prime \prime},-36 "\end{array}$ \\
\hline 2 & HRGA & $1 "$ & 0 & $\begin{array}{c}\text { 3",4",5", } \\
6 "\end{array}$ & $7 ", 6 "$ & $28 ”, 29 ”, 32 "$ & $\begin{array}{l}\text { 9",-27”,30", } \\
-31 ", 33,,-36 ",\end{array}$ \\
\hline 3 & Training QA & $0 "$ & 0 & $\begin{array}{c}\text { 1",2",4", } \\
\text { 5",6" }\end{array}$ & $7 ", 6 "$ & $28 ”, 29 ”, 32 "$ & $\begin{array}{l}\text { 9",-27”,30", } \\
-31 ", 33 ",-36 ",\end{array}$ \\
\hline 4 & Ruang QA & $0 "$ & 0 & $\begin{array}{l}\text { 1",2",3", } \\
\text { 5"6,", }\end{array}$ & $7 ” .6 ”$ & $28 ”, 29 ”, 32 ”$ & $\begin{array}{l}9 ",-27 ”, 30 ", \\
-31 ", 33 ",-36 "\end{array}$ \\
\hline 5 & Technical Office & $0 "$ & 0 & $\begin{array}{c}\text { 1",2",3", } \\
\text { 4",6" }\end{array}$ & $7 ", 6 "$ & $28 ", 29 ”, 32 ”$ & $\begin{array}{l}\text { 9",-27”,30", } \\
-31 ", 33,,-36 ",\end{array}$ \\
\hline 6 & Ruang 5S dan DC & $0 "$ & 0 & $\begin{array}{c}\text { 1",2”,3", } \\
4 ”, 5 "\end{array}$ & $7 ”, 6 "$ & $28 ”, 29 ”, 32 ”$ & $\begin{array}{l}\text { 9",-27”,30", } \\
-31 ", 33 ",-36 "\end{array}$ \\
\hline 7 & Material Store & $8 "$ & $\begin{array}{c}9 ",-12 ”, 14 ",- \\
27 "\end{array}$ & 0 & $2 ",-6 "$ & $\begin{array}{c}\text { 1",29",32", } \\
\text { 33" }\end{array}$ & $\begin{array}{l}13 ”, 28 ", 30 ", \\
31 ", 34 ",-36 "\end{array}$ \\
\hline 8 & Part Store & $7 "$ & $9 "$ & $\begin{array}{c}10 ",-12 ", 16 ", \\
18 ",-27 "\end{array}$ & $\begin{array}{c}\text { 2",-6",13", } \\
14 ", 16 "\end{array}$ & $\begin{array}{c}\text { 1",29”,32", } \\
33 "\end{array}$ & $\begin{array}{l}13 ", 25 ", 30 ", \\
31 " 34 ",-36 "\end{array}$ \\
\hline 9 & $\mathrm{IM}$ & 0 & $7 ”, 8 ”, 10 ”$ & $\begin{array}{c}11 ",-12 ", 14 ", \\
-27 "\end{array}$ & 0 & $29 ”, 32 ”, 33 ”$ & $\begin{array}{l}\text { 1",-6",13", } \\
25 ", 30 ", 31 " \\
, 34 ",-36 "\end{array}$ \\
\hline 10 & Ruang Moldshop & $11 ", 12 "$ & 7”,9” & $8 ”, 14 ",-27 ”$ & 0 & 29”,32”,33” & $\begin{array}{c}\text { 1",-6”,13”, } \\
25 ", 30 ”, 31 " \\
\text {,34",-36" }\end{array}$ \\
\hline 11 & WIP & $10 ", 12 "$ & $7 ”$ & $\begin{array}{c}\text { 8",9",14', } \\
27 "\end{array}$ & 0 & $29 ", 32 ”, 33 "$ & $\begin{array}{c}\text { 1",-6”,13", } \\
25 ", 30 ”, 31 ” \\
\text {,34",-36" }\end{array}$ \\
\hline 12 & Mold Cleaning & $10 ", 11 "$ & $7 ”, 34 ”$ & $\begin{array}{c}8 ", 9 ", 14 ' \\
-27 "\end{array}$ & 0 & 29”,32”,33” & $\begin{array}{c}\text { 1",-6",,13", } \\
25 ", 30 ", 31 ” \\
, 35 ",-36 "\end{array}$ \\
\hline 13 & IPP & 0 & 0 & 0 & 0 & $29 ”, 32 ”, 33 "$ & $\begin{array}{l}\text { 1",-28",30", } \\
31 ", 34,,-36 "\end{array}$ \\
\hline 14 & Monomer & $15 ”$ & $7 ”$ & $\begin{array}{c}9 ",-12 ", 16 ", \\
-27 ”\end{array}$ & $8 "$ & 29”,32”,33” & $\begin{array}{l}\text { 1",-6",13", } \\
28 ”, 30 ”, 31 ", \\
34 ", 35 ", 36,\end{array}$ \\
\hline 15 & Resin & $14 ", 16 "$ & $7 "$ & $\begin{array}{c}9 ",-12 ", 17 " \\
-27 "\end{array}$ & $8 "$ & 29”,32”,33” & $\begin{array}{l}\text { 1",-6",13", } \\
28,, 30 ", 31 ", \\
34 ", 35 ", 36 ",\end{array}$ \\
\hline 16 & Fiilling PLC & $15 "$ & $7 ”, 17 "$ & $\begin{array}{l}\text { 8",-12”,15”, } \\
18 ",-27 "\end{array}$ & 0 & 29”,32”,33” & $\begin{array}{l}\text { 1",-6",,13", } \\
28 ”, 30 ", 31 ", \\
34 ", 35 ", 36 ",\end{array}$ \\
\hline 17 & Curing Area & 0 & $7 ”, 16 ", 18 "$ & $\begin{array}{c}\text { 14",15",19”, } \\
-27 "\end{array}$ & $8 "$ & 29”,32”,33” & $\begin{array}{l}\text { 1",-6",,13", } \\
28,, 30 ", 31 ", \\
34 ", 35 ", 36 ",\end{array}$ \\
\hline 18 & Storage Gasket & $19 "$ & $7 ”, 17 ”$ & $\begin{array}{l}\text { 8”,12”,14”, } \\
-16 ", 20 ” 27 ”\end{array}$ & 0 & 29”,32”,33” & $\begin{array}{l}\text { 1",-6",13", } \\
28,, 30 ”, 31 ", \\
34 ", 35,, 36 ",\end{array}$ \\
\hline 19 & $\begin{array}{l}\text { R. Lenspick } \\
\text { PLC }\end{array}$ & $18 ”, 20 "$ & $7 "$ & $\begin{array}{l}\text { 8”,-12",14", } \\
-17 ", 21 ",-27 "\end{array}$ & 0 & $29 ”, 32 ”, 33 ”$ & $\begin{array}{l}\text { 1",-6",13", } \\
28 ”, 30 ”, 31 ", \\
34 ”, 35 ", 36,\end{array}$ \\
\hline 20 & R. Packing PLC & $19 ", 21 "$ & $7 ”$ & $\begin{array}{l}\text { 8”,-12”,14”, } \\
-18 ”, 22 ”,-27\end{array}$ & 0 & 29”,32”,33” & $\begin{array}{l}\text { 1",-6",,13", } \\
28,, 30 ", 31 ", \\
34 ", 35 ", 36 ",\end{array}$ \\
\hline 21 & Degasketing PLC & $20 "$ & $7 ”, 22 ”$ & $\begin{array}{l}\text { 8",-12",14", } \\
-20^{\prime \prime}, 24 ",-27 "\end{array}$ & 0 & 29”,32”,33” & $\begin{array}{l}\text { 1",-6",13", } \\
28,, 30 ", 31 ", \\
34,, 35,, 36 ",\end{array}$ \\
\hline 22 & Packing Mold & 0 & $7 ”, 21 ”, 23 "$ & $\begin{array}{l}8 ”,-12 ", 14 " \\
-20 ", 24 ",-27 "\end{array}$ & 0 & $29 ”, 32 ”, 33 "$ & $\begin{array}{l}\text { 1",-6",,13", } \\
28,, 30 ”, 31, \\
34,, 35,, 36,\end{array}$ \\
\hline 23 & Area T. PLC & 0 & $7 ”, 22 ”, 24 "$ & $\begin{array}{l}8 ",-12^{\prime \prime}, 14^{\prime \prime}, \\
-21 ", 25^{\prime \prime},-27 ”\end{array}$ & 0 & 29”,32”,33” & $\begin{array}{l}\text { 1",-6",13", } \\
28,, 30 ", 31 ", \\
34,, 35,, 36 ",\end{array}$ \\
\hline 24 & Palet Area & 0 & $7 ”, 23 ”, 25 "$ & $\begin{array}{l}\text { 8",-12",14", } \\
-22 ", 26 ”, 27 ”\end{array}$ & 0 & 29”,32”,33” & $\begin{array}{l}\text { 1",-6",13", } \\
28,, 30,, 31,, \\
34,35, " 36, \\
1 ",-6 ", 13,\end{array}$ \\
\hline 25 & AR (Anti Refleksi) & $26 "$ & $7 ”, 24 "$ & $\begin{array}{l}\text { 8",-12",14", } \\
-23 ", 27 ”\end{array}$ & 0 & $29 ”, 32 ”, 33 "$ & $\begin{array}{l}28,, 30,, 31, \\
34,, 35,, 36,\end{array}$ \\
\hline
\end{tabular}




\begin{tabular}{|c|c|c|c|c|c|c|c|}
\hline \multirow{2}{*}{ No } & \multirow{2}{*}{ Ruang } & \multicolumn{6}{|c|}{ Derajat Keterdekatan } \\
\hline & & A & E & I & $\mathrm{O}$ & $\mathrm{U}$ & $X$ \\
\hline 26 & R. Physical Test & $25 "$ & $27 ”$ & $\begin{array}{l}\text { 8", 12", } \\
14 ",-24 "\end{array}$ & 0 & $29 ”, 32 ”, 33 ”$ & $\begin{array}{c}1 ",-6 ", 13 ", \\
28,, 30 ", 31 ", \\
34 ", 35 ", 36 "\end{array}$ \\
\hline 27 & FGS & 0 & 0 & $\begin{array}{c}8 ",-12 ", 14 ", \\
-25 "\end{array}$ & 0 & 29”,32”,33” & 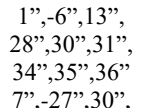 \\
\hline 28 & Toilet & 0 & 0 & 0 & $29 "$ & $1 ”,-6 ”, 32 "$ & $\begin{array}{c}31 ", 33,, 34, ", \\
35,36 ",\end{array}$ \\
\hline 29 & Masjid & 0 & 0 & 0 & $28 ”$ & 1",-27”29” & $\begin{array}{l}30 ", 31 ", 33 ", \\
34 ", 35,36, \\
1 ",-29,31 ",\end{array}$ \\
\hline 30 & Kantin & 0 & 0 & 0 & 0 & $29 "$ & $\begin{array}{c}33 ", 34 ", 35 ", \\
36 "\end{array}$ \\
\hline 31 & Parkir Motor & 0 & 0 & 0 & 0 & $29 "$ & $\begin{array}{c}\text { 1",-30",31", } \\
\text { 33",34",35", } \\
36 ",\end{array}$ \\
\hline 32 & Plant 1 & 0 & 0 & 0 & 0 & $1 ",-31 "$ & $\begin{array}{c}\text { 33",34",35", } \\
36 "\end{array}$ \\
\hline 33 & Compressor & 0 & 0 & $34 "$ & 0 & $7 ”,-27 ’, 35 ”$ & $\begin{array}{l}\text { 1",-6",28", } \\
-32 ", 35 ", 36 "\end{array}$ \\
\hline 34 & $\begin{array}{l}\text { WTP \& R. } \\
\text { Electrical }\end{array}$ & 0 & $12 ”$ & $33 "$ & 0 & 0 & $35 ", 36 "$ \\
\hline 35 & WWTP & 0 & 0 & 0 & 0 & $33 "$ & $\begin{array}{c}\text { 1",--32",34", } \\
36 "\end{array}$ \\
\hline 36 & TPA & 0 & 0 & 0 & 0 & 0 & $\begin{array}{l}1 ", \\
-36 "\end{array}$ \\
\hline
\end{tabular}

3. Membuat Area Allocation Diagram (AAD): Dibuat sebagai bentuk akhir dalam perancangan tata letak pabrik setelah dilakukannya penyusunan pada Activity Relationship Chart (ARC). Berikut adalah Area Allocation
Diagram Sekarang yaitu pada Gambar 3. dan Area Allocation Diagram Usulan yaitu pada Gambar 4. Hal ini berfokus pada area plant 3 yang terjadi perpindahan ruang seperti pada Gambar 3. di bawah ini:

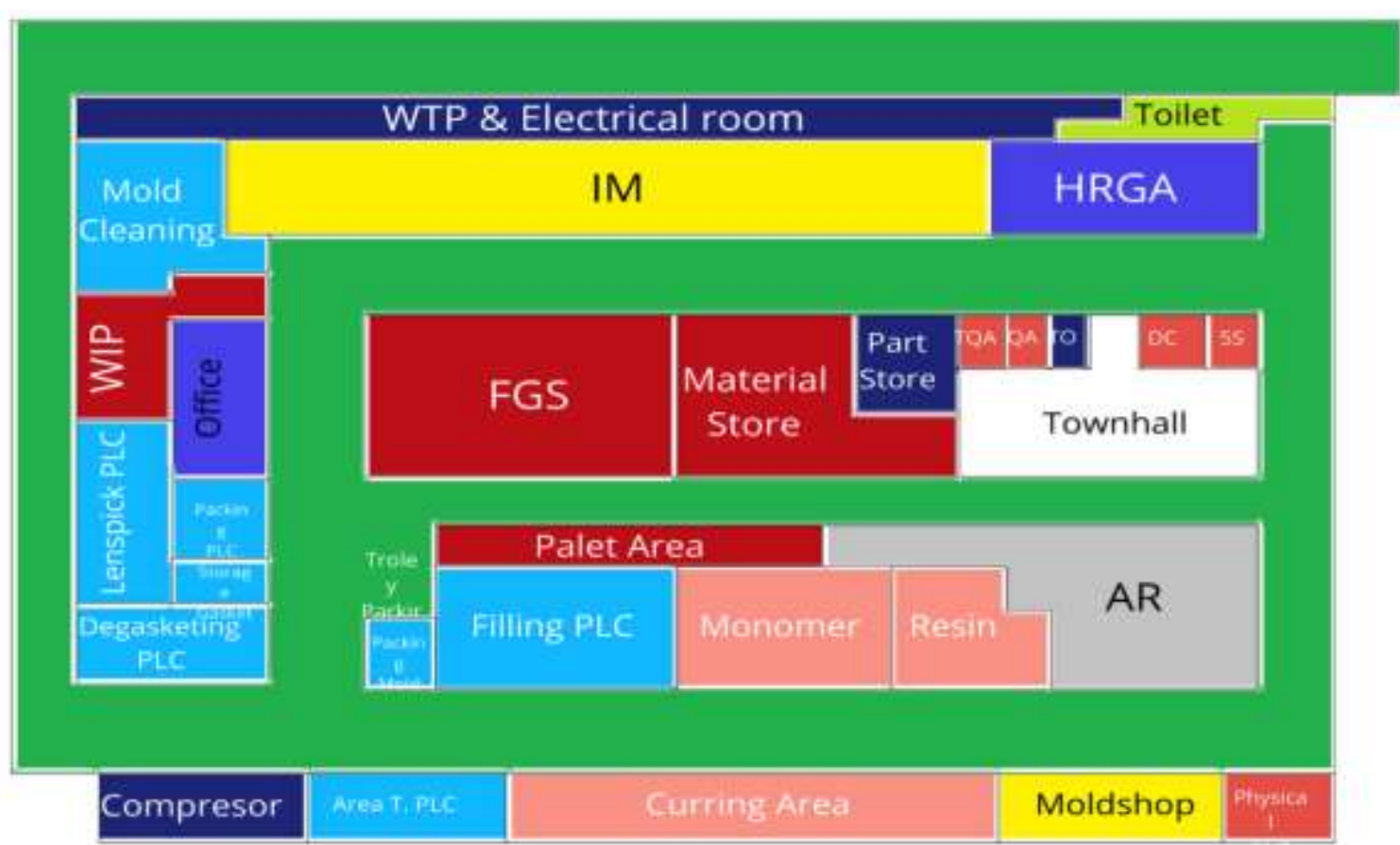

Gambar 3. Hasil Activity Relationship Chart (ARC) 
Gambar 3. di atas menunjukan bahwa terdapat ruang yang tidak aktif yaitu ruang town hall, dengan warna putih.
Sedangkan ruang office terletak di antara ruang untuk kegiatan produksi.

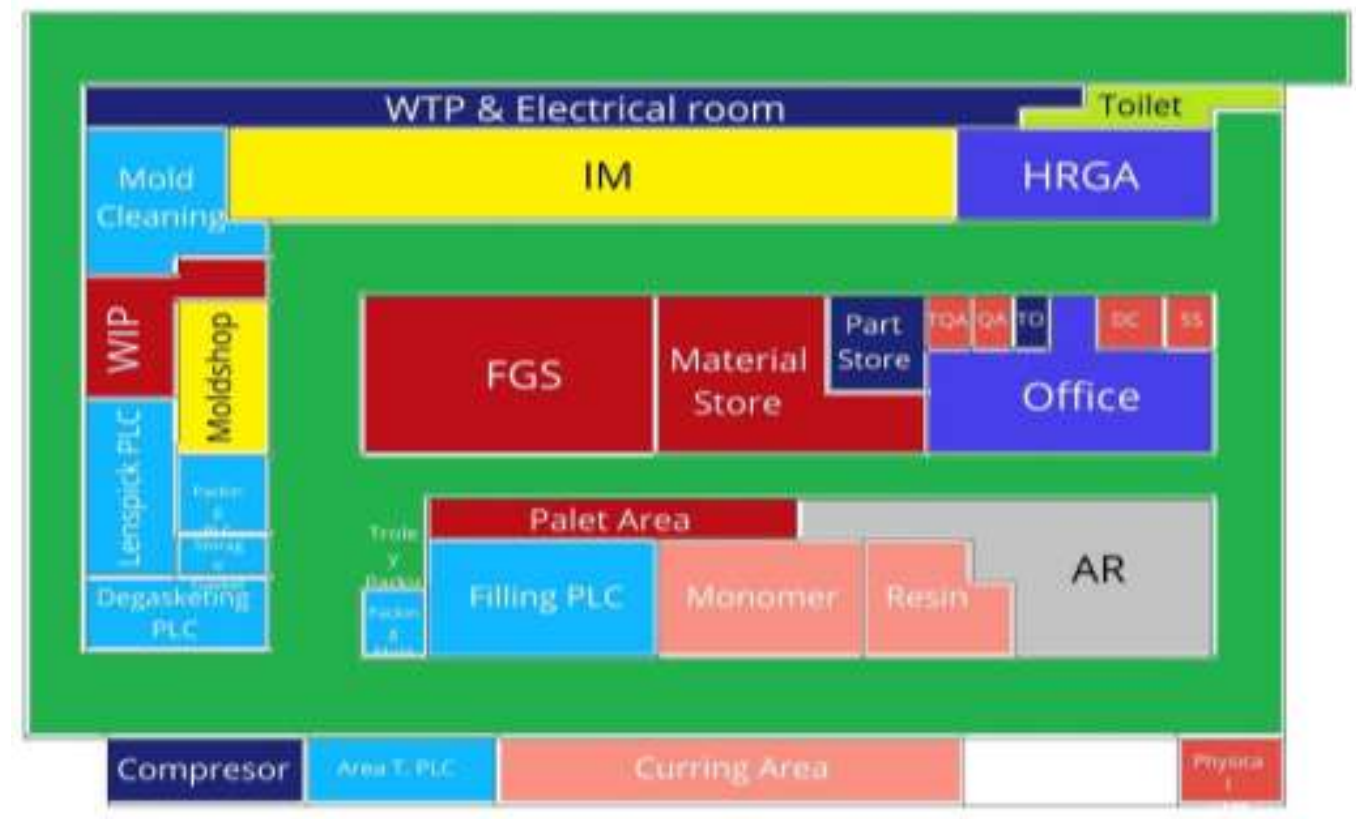

Gambar 4. Hasil Activity Relationship Chart (ARC)

Gambar 4. di atas menunjukkan bahwa office dipindahkan ke ruang yang lebih besar yaitu ruang town hall yang sebelumnya. Sedangkan ruang mold shop dipindahkan menjadi terletak pada ruang office sebelumnya.
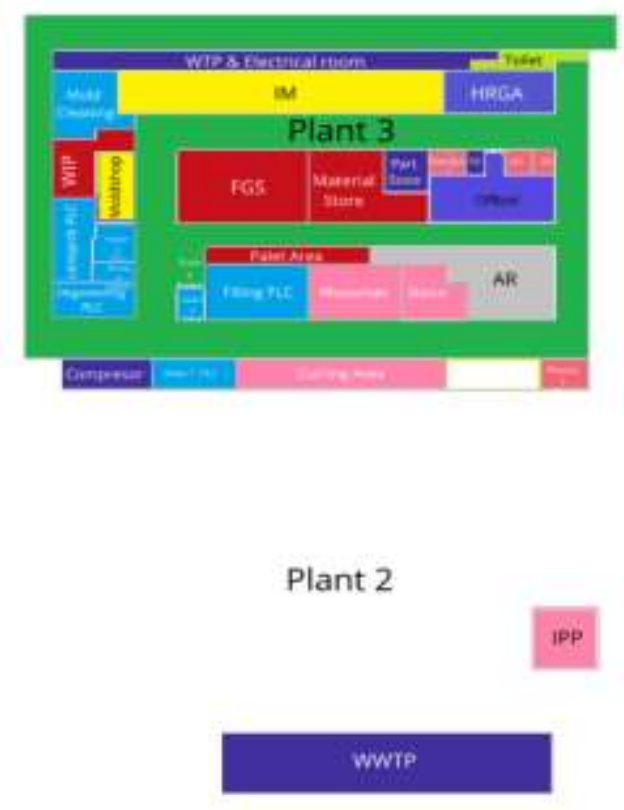

Gambar 5. Layout Usulan PT. XYZ ini:

4. Membuat Layout Usulan: Setelah dilakukan tahapan di atas maka tahap terakhir adalah membuat layout usulan secara keseluruhan. Berikut adalah gambar layout usulan untuk PT. XYZ yang terdapat pada Gambar 5. di bawah

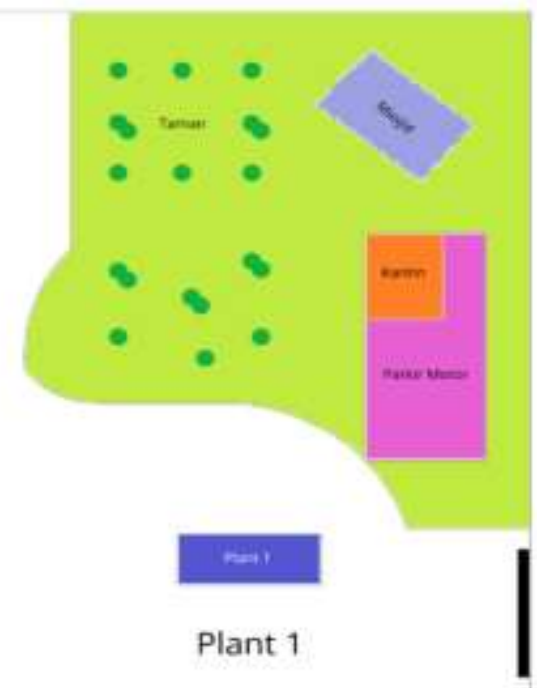


Pada Gambar 5. di atas dapat dilihat bahwa area yang paling aktif berada pada plant 3 . Plant 3 adalah produksi utama PT. XYZ berjalan dan juga sebagai area yang di dalamnya terdapat kantor sebagai pusat informasi dan pemberkasan perusahaan. Kemudian pada plant 1 dan 2 hanya beberapa area saja yang masih aktif digunakan untuk keperluan perusahaan.

Metode Activity Relationship Chart (ARC) diterapkan dalam penelitian ini sebagai metode untuk perencanaan tata letak pabrik atau plant layout. Berdasarkan hasil usulan untuk perusahaan dengan cara mendekatkan hubungan antar departemen dan berdasarkan aktivitas-aktivitas tertentu. Tentu saja hal ini akan meminimalkan kembali kegiatan proses produksi yang lebih baik. Hasil dari beberapa penelitian sebelumnya menunjukkan penggunaan metode activity relationship chart (ARC) dapat memecahkan permasalahan yang terjadi. Permasalahan dalam layout proses produksi yang seharusnya dapat diminimalkan kembali. Hasil yang ditawarkan dalam penelitian ini berupa usulan layout proses produksi yang baik, sesuai dengan hasil kajian literatur yang dilakukan.

\section{KESIMPULAN}

Hasil dari penelitian memberikan usulan plant layout yang tersistematis untuk proses produksi yang lebih baik. Maka penerapan metode activity relationship chart (ARC) sebagai metode usulan tata letak pabrik yang lebih baik. Perbedaan sebelum dan sesudah usulan terletak pada:

1. Town Hall sebagai ruang yang kosong yang tidak terpakai pada daerah plant 3 dihilangkan. Selain itu ditukar fungsinya sebagai office pada layout usulan. Agar ruang untuk office menjadi lebih luang.
2. Ruang office pada layout sekarang berada di antara ruangan produksi, yaitu ruang WIP (Work in Process) dan juga ruang packing PLC. Sedangkan pada layout usulan ruang office letaknya berdekatan dengan ruang HRGA (Human Resource and General Affair) untuk memudahkan aktivitas pusat kantor dan aktifitas pemberkasan.

3. Untuk layout usulan ruang office yang lama difungsikan menjadi ruang mold shop dengan tujuan mengefektifkan dan mengefisiensi berjalannya proses produksi pada perusahaan.

Hasil saran dari perencanaan tata letak pabrik di PT. XYZ dilakukan dengan melakukan perpindahan ruangan yang diperbaiki. Terletak pada ruang office dan juga ruang moldshop, ruang tersebut dipindahkan dengan alasan untuk memaksimalkan penggunaan ruang pada perusahaan. Selain itu juga dipindahkan berdasarkan hubungan aktivitas dalam jalannya proses produksi.

\section{DAFTAR PUSTAKA}

Agustina, D., Maukar, A. L., \& Dewi, D. R. Perencanaan Produksi dan Perbaikkan Tata Letak di PT. Berkat Anugrah Alam Cemerlang. Widya Teknik, 184-195. 2007

Ampuh, H. R., \& Setiawan, H. Tata Letak Pabrik. Yogyakarta: CV. Andi Offset. 2008

Apple, J. M. Tata Letak Pabrik dan Pemindahan Bahan. Bandung: Institut Teknologi Bandung. 1990

Ariani, D. W. Manajemen Operasi Jasa. Yogyakarta: Graha Ilmu. 2009

Haming, M., \& Nurnajamuddin, M. Manajemen Produksi Modern Operasi Manufaktur dan Jasa. Jakarta: Bumi Aksara. 2011 
Heizer, J., \& Render, B. Manajemen Operasi. Jakarta: Salemba Empat. 2009.

Iskandar, N. M., \& Fahin, I. S. Perancangan Tata Letak Fasilitas Ulang (Relayout) untuk Produksi Truk di Gedung Commercial Vehicle (CV) PT. Mercedes Benz Indonesia. Jurnal PASTI, 66-75. 2015.

Morena, Y., \& Siska, M. Perancangan Ulang Tata Letak Fasilitas Pabrik Pembuatan Batu Bata (Studi Kasus: Kulim, Pekanbaru). SNTIKI III, 405413. 2011.

Muther, R. Practical Plan Layout. New York: McGraw-Hill Book Company Inc. 1955.

Pramesti, M., Subagyo, H. S., \& Aprilia, A. Perencanaan Ulang Tata Letak Fasilitas Produksi Keripik Nangka dan Usulan Keselamatan Kesehatan Kerja di UMKM Duta Fruit Chips, Kabupaten Malang. Jurnal Sosial Ekonomi dan Kebijakan Pertanian, 150-164. 2019.

Pratiwi, I., Muslimah, E., \& Aqil, A. W. Perancangan Tata Letak Fasilitas di Industri Tahu Menggunakan Blocplan. Jurnal Ilmiah Teknik Industri, 102-112. 2012.

Purnomo, B. H., Rusdianto, A. S., \& Hamdani, M. Desain Tata Letak Fasilitas Produksi pada Pengolahan Ribbed Smoked Sheet (RSS) di Gunung Pasang Panti Kabupaten Jember. Jurnal Unej, 167-177. 2009.

Putri, R. E., \& Ismanto, W. Pengaruh Perancangan Ulang Tata Letak Fasilitas di Area Operasional Kerja Berbasis 5S untuk Pengajuan Modal Usaha. DIMENSI, 71-89. 2019.
Tarigan, U., Simbolon, R., Sembiring, M. T., Tarigan, U. P., Sembirin, N., \& Tarigan, I. R. Perancangan Ulang dari Simulasi Tata Letak Fasilitas Produksi Gripper Rubber Seal dengan Menggunakan Algoritma Corelap, Aldep, dan Flexsim. Jurnal Sistem Teknik Industri, 74-84. 2019.

Wignjosoebroto, S. Tata Letak Pabrik dan Pemindahan Bahan. Surabaya: Guna Widya. 2009.

Yohanes, A. Perencanaan Ulang Tata Letak Fasilitas di Lantai Produksi Produk Teh Hijau dengan Metode From To Chart untuk Meminimumkan Material Handling di PT. Rumpun Sari Medini. Dinamika Teknik, 59-71. 2011.

Yulianti, R., Saleh, A., \& Bakar, A. Usulan Perancangan Tata Letak Fasilitas Perusahaan Garmen CV. X dengan Menggunakan Metode Konvensional. Jurnal Online Institut Teknologi Nasional, 72-83. 2014. 